\title{
Immunobiology of Thymic Epithelial Tumors: Implications for Immunotherapy with Immune Checkpoint Inhibitors
}

\author{
Valentina Tateo ${ }^{1} \mathbb{1}$, Lisa Manuzzi ${ }^{1}$, Andrea De Giglio ${ }^{1}$, Claudia Parisi ${ }^{1}$, \\ Giuseppe Lamberti ${ }^{1,2, *(D)}$, Davide Campana ${ }^{2}$ and Maria Abbondanza Pantaleo ${ }^{2}$ \\ 1 Department of Experimental, Diagnostic and Specialty Medicine, Policlinico di Sant'Orsola University \\ Hospital, Via P. Albertoni 15, 40138 Bologna, Italy; valentina.tateo@studio.unibo.it (V.T.); \\ lisa.manuzzi@studio.unibo.it (L.M.); andrea.degiglio@studio.unibo.it (A.D.G.); \\ claudia.parisi4@studio.unibo.it (C.P.) \\ 2 Oncologia Medica, Azienda Ospedaliero-Universitaria di Bologna, Via Albertoni 15, 40138 Bologna, Italy; \\ davide.campana@unibo.it (D.C.); maria.pantaleo@unibo.it (M.A.P.) \\ * Correspondence: giuseppe.lamberti8@unibo.it
}

Received: 30 October 2020; Accepted: 26 November 2020; Published: 28 November 2020

check for updates

\begin{abstract}
Thymic epithelial tumors (TETs) are a group of rare thoracic malignancies, including thymic carcinomas (TC) and thymomas (Tm). Autoimmune paraneoplastic diseases are often observed in TETs, especially Tms. To date, chemotherapy is still the standard treatment for advanced disease. Unfortunately, few therapeutic options are available for relapsed/refractory TETs. In the last few years, the deepening of knowledge on thymus' immunobiology and involved altered genetic pathways have laid the foundation for new treatment options in these rare neoplasms. Recently, the immunotherapy revolution has landed in TETs, showing both a dark and light side. Indeed, despite the survival benefit, the occurrence of severe autoimmune treatment-related adverse events has risen crescent uncertainty about the feasibility of immunotherapy in these patients, prone to autoimmunity for their cancer biology. In this review, after summarizing immunobiology and immunopathology of TETs, we discuss available data on immune-checkpoint inhibitors and future perspectives of this therapeutic strategy.
\end{abstract}

Keywords: thymic epithelial tumors; thymoma; thymic carcinoma; immunobiology; autoimmunity; immuno-oncology; immune check-point inhibitors; biomarkers; PD-L1; immune-related adverse events

\section{Introduction}

Thymic epithelial tumors (TETs) are a group of rare thoracic malignancies including thymic carcinomas (TC) and thymomas (Tm), with an annual incidence rate ranging between 0.9 and 2.3 per million [1]. Tms are further classified into type A, atypical type A, type AB, B1, B2 and $\mathrm{B} 3$, depending on the histopathological feature of epithelial tumor cells and the proportion of the lymphocytic component [2,3]. While TC is an aggressive disease with high metastatic potential, Tms are indolent slow-growing tumors, but are often associated with autoimmune paraneoplastic syndromes, such as myasthenia gravis (MG) $[4,5]$.

Upfront surgery is the main treatment strategy for TETs: the achievement of complete resection (R0) together with tumor stage at diagnosis is the most important prognostic factors at baseline. In fact, the 5-year overall survival after radical surgery is $90 \%$ for stages I and II, $60 \%$ in stage III and less than $25 \%$ for stage IV TETs $[4,6-8]$. Post-operative treatment with adjuvant intent (either chemotherapy, 
radiotherapy or concomitant chemoradiotherapy) can be considered on an individual basis depending on stage, margin infiltration and histology subtype $[4,6,7,9,10]$.

Unresectable TETs should undergo systemic polychemotherapy, but no randomized clinical trial has clarified which regimen should be considered as the standard of care $[4,6,7]$. Polychemotherapy with cisplatin, doxorubicin and cyclophosphamide is the first choice for Tms, yielding an overall response rate (ORR) of 50\% and a median duration of response (mDOR) of 11.8 months [11], while the combination of carboplatin and paclitaxel is preferred for TCs, and yields an ORR of $21.7 \%$ and a median progression-free survival (mPFS) of 5 months [12]. The second and subsequent lines of treatment need expert evaluation, since available data are derived from non-randomized prospective and retrospective studies as well as case reports [4,6,7].

TET patients often present with immune-mediated paraneoplastic syndromes. The role of thymus in the development of adaptive immunity and the altered molecular pathways involved in TET might explain the high rate of paraneoplastic syndromes in these patients [13-16]. Immunotherapy with immune checkpoint inhibitors is being investigated in TETs, yielding interesting response rates and survival outcomes. However, severe toxicity has been observed in TET patients secondary to abnormal immune responses promoted by immune checkpoint inhibition, thus limiting their routine application in clinical practice. We reviewed the most recent understanding of TET immunopathology, and existing data on immunotherapy to put into frame the immune-related events in TET patients and provide a focus for ongoing studies and future perspectives in the treatment of this rare group of diseases.

\section{Immunobiology of Thymus}

Thymus, together with bone marrow, is a primary lymphoid organ and is responsible for T-cell development. An outer capsule, a cortex and a medulla can be recognized in the thymus structure.

Thymic epithelial cells derive from the pharyngeal endoderm and are differentially organized in a loose net in the cortex, while they cluster in solid cordons in the medulla, as well as structures known as Hassall corpuscles. Lymphocytes, named "T-cells" after thymus, derive from thymocytes and are intermingled with epithelial cells [17]. T-cell progenitors move through the thymic structure and undergo several transformations as they differentiate in the thymus, before becoming mature T-cells (Figure 1). The most immature CD3+CD4-CD8- (double negatives, DN) thymocytes can differentiate in the cortex into $\mathrm{CD} 3+\mathrm{CD} 4+\mathrm{CD} 8+$ (double positive, DP) cells only after a process called $\beta$ selection, that consists of rearrangement and expression of functional T-cell receptors (TCR) $\beta$ chains $[17,18]$. DP thymocytes then rearrange the TCR $\alpha$ chain genes and express TCR- $\alpha / \beta$, and undergo positive and negative selection. By positive selection, only those thymocytes that have a TCR capable of binding the Major Histocompatibility Complex (MHC) expressed on thymic epithelial cells are preserved. CD8 functions as a coreceptor to bind to MHC class I, while CD4 binds MHC class II. Only positively selected thymocytes polarize towards a persistent expression of either CD4 or CD8, depending on their specificity, and can mature into either CD4+ or CD8+ single positive (SP) T-cells. SP cells migrate in the medulla, where negative selection takes place: all autoreactive thymocytes binding with a high affinity to self-peptides presented on MHC I and MHC II are eliminated by apoptosis $[17,18]$.

Auto Immune Regulator (AIRE) is a transcriptional factor highly expressed in medullary thymic epithelial cells (mTECs), which plays a pivotal role in T-cell negative selection. Indeed, it promotes the ectopic transcriptional activity of a large number of chromosomal locations, which in turn favors the expression of tissue-restricted antigens (TRAs) selectively expressed in specific tissues [19]. On the other hand, as some TRAs are also expressed by tumors, TRAs expression in mTECs, determines a cancer-antigen specific tolerance, leading to a reduced antitumor immune response [20]. Recently, the forebrain embryonic zinc finger-like protein 2 (Fezf2) has been described as a new key transcription factor in the negative selection process. Fezf2 is selectively expressed in thymic medullary epithelial cells, it regulates a large number of TRAs and suppresses the onset of an autoimmune response. Fezf2 and AIRE regulate the expression of different TRAs with only partial overlap [21]. 




Figure 1. T-cell development process. DN: double negative; DP: double positive; MHC: major histocompatibility complex; TCR: T-cell receptor; AIRE: Auto Immune Regulator; TRA; tissue-restricted antigen; Fezf2: forebrain embryonic zinc finger-like protein 2.

Nonetheless, negative selection is not completely efficient, since some autoreactive T-cells could escape thymic selection and be released into the bloodstream. Peripheral tolerance mechanisms are critical to silence these cells and act through induction of anergy, deletion, or suppression by regulatory T-cells (T-reg, CD4+Foxp3+). Although many immune cells are involved in this process, dendritic cells (DCs) play a central role since they can promote peripheral tolerance by presenting the antigen to T-cells in steady-state, that is in absence of pro-inflammatory stimuli [22]. T-cell costimulatory pathways also contribute to central and peripheral immunotolerance, with a major role of the Programmed Death 1 (PD-1) and its ligands, Programmed Death Ligand 1 (PD-L1) which is expressed in the thymic cortex, and Programmed Death Ligand 2 (PD-L2) which is expressed in the thymic medulla. Binding of PD-1 to PD-L1/2 inhibits T-cell activation, especially in the case of persistent antigenic stimulation, such as self-antigens encounter, chronic infections or tumors. PD-1 pathway, in fact, contributes to autoimmunity prevention, directly causing T-cell exhaustion and promoting an immunosuppressive tumor microenvironment, partly by T-reg induction [23].

\section{Immunopathology of TETs}

Thymus pivotal role in the immune system development explains the high rate of autoimmune phenomena in TET patients. In fact, approximately $40 \%$ of Tm patients suffer systemic symptoms despite being affected by a localized disease, because of the development of autoimmune and paraneoplastic syndromes [24].

The most common paraneoplastic autoimmune syndrome associated with TETs is MG, which occurs in approximately $30 \%$ of all Tm patients [25,26]. Nevertheless, MG incidence can vary, depending on the histological subtype: it is approximately $15 \%$ in type $\mathrm{A}$ Tms, $20 \%$ in type $\mathrm{AB}$, $40 \%$ in type B1, 50\% in type B2, 50\% in type B3 and $<5 \%$ in TCs patients [4]. Furthermore, among Tm patients, $4-7 \%$ of those with MG have more than one paraneoplastic syndrome, while approximately $10-15 \%$ of those without MG have symptoms from a different paraneoplastic condition [25,26]. MG is caused by the presence of autoantibodies against the nicotinic acetylcholine receptor (AchR) that cause an autoimmune disorder of the postsynaptic portion of the neuromuscular plaque, whose clinical presentation is characterized by fluctuating skeletal muscle weakness and fatigue $[27,28]$.

Tm is also associated with other otherwise rare neurological paraneoplastic syndromes, including: limbic encephalitis, usually due to the presence of anti-Hu antibodies, Ma2 antibodies and CRMP-5 antibodies; neuromyotonia, an autoimmune potassium channelopathy; stiff person syndrome, caused by 
anti-GAD antibodies; myotonic dystrophy, an inherited disease, occasionally described in association with Tm; polymyositis, an inflammatory myopathy characterized by proximal muscular weakness, frequently associated with MG, myocarditis and autoimmune hepatitis. Non-neurological syndromes may also appear in concomitance with Tm: myocarditis with diffuse myocardium degeneration and infiltration of inflammatory giant cells is generally observed in concomitance with polymyositis and MG; Graft-Versus-Host-Disease, a T-cell mediated condition usually observed after stem cell transplantation, is also rarely seen in patients with Tm; Good syndrome, characterized by hypogammaglobulinemia with immunodeficiency involving both B- and T-cells; pure red cell aplasia, likely caused by T-cell dysfunction. Other rare autoimmune diseases such as thyroiditis, mixed connective tissue disease, paroxysmal nocturnal hematuria, acrokeratosis, systemic lupus erythematosus, pemphigus, lichen planus, conjunctivitis and cancer-associated retinopathy have been reported [25].

In contrast to Tm, TC has more aggressive clinical features with evident local invasiveness, early nodal intrathoracic dissemination and a high propensity to distant metastases, but it is not associated with paraneoplastic syndromes $[4,5]$. This may be due to the fact that, usually, there are no immature T-cells within TC, so this tumor is rarely associated with autoimmune diseases [29].

Central tolerance and immunoregulation deficiency that occur as a consequence of tumor immune-microenvironment alterations are critical in the pathogenesis of Tm-associated autoimmunity. Indeed, AIRE, AchR and Foxp3 (the transcription factor that induces T-reg phenotype) mRNA levels are lower in tumor tissue from Tm patients without MG compared to those who have developed MG [30]. Moreover, thymopoiesis, that is the maturation of T-cells occurring within the Tm, alters peripheral T-cell repertoire by primarily increasing the proportion of CD45RA+CD8+ T-cells, which is also the population that is reduced after thymectomy $[30,31]$. Furthermore, autoimmune syndromes can be associated with specific genomic alterations. A higher rate of aneuploidy was observed in Tm from patients with MG. Indeed, the analysis of intratumoral transcripts levels showed that some genes with sequence similarity to major autoimmune targets were overexpressed in $\mathrm{Tm}$ associated with MG compared to those without MG. In particular, the medium-sized neurofilament (NEFM), whose protein product exhibits immunogenic similarities with the $\mathrm{AChR} \alpha$-subunit and titin, is mainly overexpressed in MG+ A/AB Tms, while the neuronal RYR3, whose encoded protein shares homology with muscular RYR1 and cardiac RYR2, is predominantly overexpressed in MG+ B Tms [16]. Similarly, a differential expression analysis of $34 \mathrm{Tms}$ with or without $\mathrm{MG}(\mathrm{N}=16$ and $\mathrm{N}=18$, respectively) identified 140 differentially expressed genes [32]. In particular, insulin-like growth factor-binding protein (IGFBP1), Krüppel-like factor 15 (KLF15) transcription factor, pyruvate dehydrogenase kinase (PDK4) and hypoxia-inducible factor (HIF3A) were more expressed in Tm associated with MG than in those not associated with it, thus suggesting a role for these genes expression, especially HIF3A and IGBP1, in the pathogenesis of MG [32].

\section{Implications of TETs Immune Biology for the Clinic: Immunotherapy in TETs}

\subsection{General Considerations about Immunotherapy in TETs}

During transformation, cancer cells should escape surveillance by the host immune system in order to proliferate. To do so, the cancer cell abnormally expresses proteins that hamper T-lymphocyte activation despite proper antigen recognition, which are referred to as immune checkpoints [33]. The most biologically and clinically relevant immune checkpoints identified to date are PD-L1 and cytotoxic T-lymphocyte-associated protein 4 (CTLA-4), which are targeted by drugs called "immune checkpoint inhibitors" (ICI). In the last few years, the use of ICI has revolutionized the treatment and the prognosis of many cancers and has shown the ability to reach durable responses in a subset of patients [34-47]. Currently, the identification of patients likely to respond to ICI is based on three predictive factors: PD-L1 expression on tumor cells, microsatellite instability (MSI), and tumor mutational burden (TMB) [48-51]. While PD-L1 expression and MSI are clinically validated, TMB is used only in investigational studies. 
ICIs are characterized by a manageable safety profile and better tolerability to patients compared to standard chemotherapy. Nevertheless, immune checkpoint inhibition induced an all-new class of adverse events, i.e., immune-related adverse events (irAEs), that are caused by the activation of autoreactive T-cells and other immune cells against host tissues, thus mocking an autoimmune disease (AD). irAEs are commonly manageable and mild in severity, but can rarely be fatal, with a toxicity fatality rate ranging from $0.36 \%$ to $1.23 \%$ depending on the type of ICI used (lowest with anti-PD-1 and anti-PD-L1, followed by anti-CTLA-4, and highest with the combination of anti-PD1/PDL1 and anti-CTLA-4) [52,53]. Skin, thyroid, colon, lung and pituitary gland are the most commonly involved organs, with differences among drugs. Heart, nervous system and other organs can be more rarely affected with more severe toxicities [53-55]. In addition, the development of irAEs is associated with improved outcome on ICIs in different cancer types [56-59]. Patients that are candidates to receive ICIs, which are affected by a preexisting $\mathrm{AD}$ or with a predisposition to developing an $\mathrm{AD}$, need a comprehensive and prudent evaluation. In fact, patients with an $\mathrm{AD}$ or receiving an immunosuppressive therapy were usually excluded from clinical trials of ICIs, due to the possible risk for an autoimmune flare on ICIs and the reduced efficacy of ICI during immunosuppression. Nonetheless, subsequent experiences suggested that ICIs might be safe in selected patients with a preexisting $\mathrm{AD}$ and the onset of autoimmunity flares were manageable (exacerbation rate of 20-40\%) [60-62]. As for the efficacy, small case series reported complete response in patients treated simultaneously with ICIs and selective immunosuppressant therapy (e.g., tocilizumab, vedolizumab, infliximab) [63,64], while nonselective immunosuppressant drugs (e.g., corticosteroids, tacrolimus, cyclophosphamide, mycophenolate mofetil) negatively affected the prognosis of patients on ICI [65]. However, a worse outcome on steroids has been reported to be dependent on the indication because of which these are prescribed [66].

ICIs have also been investigated in rare cancers, including TETs. PD-L1 is expressed on the normal thymic cortex cells and it is also highly expressed on TETs tumor cells [29]. Tumor-reacting CD8+ T-cells and consequent IFN $\gamma$ production cause expression of PD-L1 and other immunosuppressive proteins, such as indoleamine 2,3-dioxygenase (IDO1) and Foxp3, on tumor cells as a feedback mechanism, as shown in melanoma cells [67]. In TETs, the abnormal thymic architecture and thymic epithelial cells are responsible for the development of dysfunctional thymocytes and potentially autoreactive T-cells, which are released into the circulation. These autoreactive T-cells may recognize self-antigens expressed on TET tumor cells, causing IFN $\gamma$ release, which in turn upregulates PD-L1 expression on TET tumor cells. A positive expression of PD-L1, defined as IHC score $\geq 1$ or positive staining $\geq 1 \%$, is found in around $70 \%$ of TCs and $20 \%$ of Tms (types A, AB and B), but its association with the outcome is discordant $[29,68,69]$. High PD-L1 expression in TETs, defined as an IHC score $\geq 3$ or positive staining $\geq 50 \%$, is associated in some studies with more advanced disease stage (stage III-IV in the Masaoka-Koga classification) and more aggressive histology types, such as in type B2/B3 Tm or TC [68-71]. As opposed to this, high PD-L1 expression was associated with an increased number of infiltrating cytotoxic T-lymphocytes and improved survival in a series of 25 TCs [72]. Regarding other immunosuppressive molecule expression, a retrospective study on surgically resected TETs revealed a high expression of IDO and Foxp3 in 13\% and 16\% of Tms, respectively, and both associated with high grade tumor histology, but had no survival differences. IDO and Foxp3 were overexpressed in $14 \%$ and $29 \%$ of TCs, respectively, and were not associated with stage or grade, but a longer survival in patients whose TC had low expression of IDO and high expression of Foxp3 was observed [73]. TETs are overall characterized by a low TMB, which is the lowest among adult cancers, but it is significantly higher in TCs compared to other TETs [16,74,75], while MSI has been only exceptionally described in TCs [16]. The high expression of PD-L1 provides a rationale for the use of immunotherapy in TET, but concerns are risen due to the association of TETs with the aforementioned autoimmune manifestations. In this scenario, TC might be the favorite setting for immune checkpoint inhibition, given its high PD-L1 expression levels and its high TMB, alongside with a lower incidence of autoimmune paraneoplastic syndromes compared to Tm [16]. Currently, three ICIs across four studies have been evaluated in TET 
patients (Table 1): pembrolizumab (a humanized IgG4 kappa anti-PD1 antibody), nivolumab (a fully human IgG4 anti-PD1 antibody) and avelumab (a fully human IgG1 anti-PD-L1 antibody).

Table 1. Published clinical trials of IO monotherapy in thymic epithelial tumor (TET) patients.

\begin{tabular}{|c|c|c|c|c|c|c|c|}
\hline $\begin{array}{l}\text { First Author, Year } \\
\text { (Study Name) }\end{array}$ & Phase & TC (n) & $\operatorname{Tm}(\mathrm{n})$ & $\begin{array}{l}\text { Experimental } \\
\text { Drug }\end{array}$ & $\begin{array}{l}\text { mPFS, \% } \\
(95 \% \mathrm{CI})\end{array}$ & $\begin{array}{l}\text { ORR, \% } \\
(95 \% \mathrm{CI})\end{array}$ & $\begin{array}{c}\text { G3-G4 } \\
\text { irAEs n (\%) }\end{array}$ \\
\hline $\begin{array}{l}\text { Giaccone, G., et al., } 2018 \\
\text { (NCT02364076) }\end{array}$ & II & 40 & 0 & Pembrolizumab & $\begin{array}{l}4.2 \text { months } \\
(2.9-10.3)\end{array}$ & $\begin{array}{c}22.5 \% \\
(10.8-38.5)\end{array}$ & $\begin{array}{c}6 \\
(15 \%)\end{array}$ \\
\hline $\begin{array}{l}\text { Cho, J., et al., } 2019 \\
\text { (NCT02607631) }\end{array}$ & II & 26 & 7 & Pembrolizumab & $\begin{array}{l}\text { 6.1 months } \\
(5.3-6.9)\end{array}$ & $\begin{array}{c}21.2 \% \\
(10.7-37.8)\end{array}$ & $\begin{array}{c}9 \\
(27.3 \%)\end{array}$ \\
\hline $\begin{array}{c}\text { Katsuya, Y., et al., } 2019 \\
\text { PRIMER study } \\
\text { (NCCH1505) }\end{array}$ & II & 15 & 0 & Nivolumab & $\begin{array}{c}3.8 \text { months } \\
(1.9-7.0)\end{array}$ & $\begin{array}{c}0 \% \\
(0-21.8)\end{array}$ & $\begin{array}{c}2 \\
(13.3 \%)\end{array}$ \\
\hline $\begin{array}{l}\text { Rajan, A., et al., } 2019 \\
\text { JAVELIN } \\
\text { (NCT01772004) }\end{array}$ & I & 1 & 7 & Avelumab & NA & $\begin{array}{l}57 \% \\
\text { (NA) }\end{array}$ & $\begin{array}{c}5 \\
(62.5 \%)\end{array}$ \\
\hline
\end{tabular}

IO: immuno-oncology; TC: thymic carcinoma; Tm: thymoma; mPFS: median progression free survival; CI: confidence interval; ORR: overall response rate; irAEs: immune-related adverse events; NA: not available.

\subsection{Nivolumab}

The PRIMER study is the only trial of nivolumab that investigated activity in TET patients, but it was closed early for futility at the first stage [76]. A total of 15 pretreated patients with unresectable or recurrent TC, regardless of PD-L1 expression, were enrolled in this two-stage single arm phase II trial. In total, 13 TCs $(87 \%)$ had squamous histology, nine patients $(60 \%)$ had previously received one or two lines of chemotherapy while six patients $(40 \%)$ had undergone three or more lines of therapy. Nivolumab $3 \mathrm{mg} / \mathrm{kg}$ was administered every 2 weeks until disease progression or unacceptable toxicity. The primary endpoint was ORR. No complete nor partial responses (CR, PR) was observed, 11 patients had stable disease (SD), and four patients had progressive disease (PD) as the best response. The disease control rate (DCR) was 73.3\%, the mPFS was 3.8 months (95\% CI: 1.9-7.0) and the median overall survival (mOS) was 14.1 months (95\% CI: 11.1-Not estimable).

The toxicity profile was overall manageable: there were no drug discontinuations because of AEs, the majority of AEs was mild, and only two patients presented serious irAEs (one grade 3 transaminase increase and one grade 2 adrenal insufficiency, according to Common Terminology Criteria for Adverse Events, version 4.0 grading) [76].

\subsection{Avelumab}

The JAVELIN Solid Tumor study (NCT01772004) is a phase I trial of avelumab in advanced solid tumors that enrolled a total of eight heavily pretreated TET patients (seven with Tm and one with TC) [77]. Patients had no history of Tm-associated autoimmune disease. Avelumab at doses of $10 \mathrm{mg} / \mathrm{kg}$ to $20 \mathrm{mg} / \mathrm{kg}$ every 2 weeks was administered until disease progression or intolerable toxicity, obtaining disease shrinkage in four patients (two confirmed PR and two unconfirmed PR, all in Tm patients) and stable disease in three patients (two with Tm and one with TC). Remarkably, all responders developed irAEs and had previously been treated with sunitinib, a multikinase inhibitor with an antiangiogenic effect. On the contrary, only one out of the four non-responders developed an irAE. However, avelumab was worse tolerated compared to available data in other solid tumors, and a higher-than-expected rate of severe irAEs was observed. Indeed, the incidence of grade $3 \mathrm{AEs}$ was $38 \%(\mathrm{~N}=3)$, with the same rate for grade $4 \mathrm{AEs}(38 \%, \mathrm{~N}=3)$. Overall, five patients developed severe irAEs. Specifically, one patient with a B3 Tm developed grade 3 creatine phosphokinase elevation and grade 1 transaminase elevation 2 weeks after the first avelumab administration. Another patient with a B3 Tm developed bulbar weakness, mild sensory loss in feet, facial diplegia, weakness of the tongue and hypophonia after 3 avelumab administrations. The patient obtained only a partial recovery 
after oral steroid therapy. A patient with a B2 Tm developed myositis after the first administration of avelumab. Another patient with a B2 Tm developed progressive dysphagia and generalized muscle weakness after the first administration of avelumab. This patient required intensive care unit admission with intubation and mechanical ventilation because of progressive dyspnea and dysphagia and was treated with intravenous steroid therapy that led to only partial recovery. Lastly, one patient with a B1 Tm developed grade 3 enteritis with subsequent grade 4 hypokalemia after 11 administrations of avelumab.

Correlative analyses showed that pretreatment absolute lymphocyte count was higher in responders compared to non-responders, while frequencies of B cells, regulatory T-cells, conventional dendritic cells, and natural killer cells were lower in responders compared to non-responders. Additionally, T-cell receptor diversity in pre-therapy peripheral blood mononuclear cells (PBMC) was higher in patients who responded and developed irAEs compared to those who did not. PD-L1 expression could only be analyzed in two tumor samples and thus its association with the response could not be determined in this study. Interestingly, intratumoral immune infiltrates evaluated on two paired biopsies (pre- and post-treatment) showed that the immune pre-treatment infiltrate mainly composed of immature T-cells, shifted towards predominantly mature CD8+ T-cells infiltrate in the patient whose Tm responded to treatment, while it kept an immature T-cells predominance in the patient whose Tm remained stable. In addition, in the patient who achieved a partial response and developed immune-related enteritis, HLA I expression was increased in post-treatment biopsies of the tumor and gastrointestinal tract [77].

\subsection{Pembrolizumab}

Pembrolizumab was tested on patients with recurrent TC in a phase II trial [78]. Forty patients progressing on chemotherapy were included, while patients with a history of autoimmune disease were excluded. The predominant histology was squamous carcinoma $(48 \%)$, followed by poorly differentiated (32\%) and neuroendocrine (15\%) carcinoma. Pembrolizumab was given at a $200 \mathrm{mg}$ every 3 weeks dose for up to 2 years or until disease progression or intolerable toxicity. ORR, which was the primary endpoint, was $22.5 \%$ with a DCR of $75 \%$ ( $3 \%$ of CRs, $20 \%$ of PRs and $53 \%$ of SDs).

The most common grade 3-4 irAEs were increased aspartate aminotransferase $(\mathrm{N}=5,13 \%)$ and alanine aminotransferase $(\mathrm{N}=5,13 \%)$, while one or more severe autoimmune toxicity was observed in six patients $(15 \%)$. In particular, two patients $(5 \%)$ developed polymyositis and myocarditis after two administrations of pembrolizumab. High-dose steroid therapy until recovery and pacemaker placement were needed for both patients. In one of these patients, an increased frequency of some T-cell receptor clones in post-treatment blood samples was observed.

PD-L1 expression assessment, available in 37 patients, showed a high expression of PD-L1 (expression of at least $50 \%$ of the tumor cells) in $27 \%$ of TCs. Among patients with high PD-L1 expression, it was reported that five had a PD and six a CR/PR. Among the 27 TCs with low PD-L1 expression (73\%), 23 had PD (85\%). In a post-hoc analysis, a benefit in terms of PFS and OS was observed in patients whose TC had high PD-L1 expression (median PFS: 24 months vs. 2.9 months-median OS: not reached vs. 15.5 months, in the PD-L1 high vs. PD-L1 low group, respectively).

A NanoString gene expression profiling was performed in 33 patients, revealing a higher expression of an 18-gene T-cell-inflamed interferon- $\gamma$ gene profile in responders compared to non-responders. Targeted exome sequencing was also conducted in 36 patients. There was a median of 3 mutations per patient (range 0-12) and TP53 was the most commonly mutated gene $(\mathrm{N}=13,36 \%)$. TP53 mutations were more frequent in patients with low or no PD-L1 expression, while CYLD mutation $(\mathrm{N}=5)$ was associated with high PD-L1 expression. A post-hoc analysis showed a correlation between TP53 mutation and shorter OS. There was also a non-significant trend between CYLD mutation and longer PFS and OS [78]. GTF2I mutation, a common mutation in Tm but rare in TC [79], was observed in a patient who developed a severe irAE [78]. 
Another phase II trial of pembrolizumab enrolled 33 TET patients (26 with TC and 7 with Tm) after progression to at least one line of platinum-based chemotherapy [80]. Pembrolizumab $200 \mathrm{mg}$ was given every 3 weeks for 2 years or until disease progression or intolerable toxicity. Patients with an autoimmune disease requiring systemic treatment within the past year or with a history of severe autoimmune disease were excluded. A total of 19 patients (57.3\%) had received at least two prior lines of chemotherapy, while $10(30.3 \%)$ had received three or more lines of chemotherapy. In total, 19 of 26 patients with TC had squamous cell carcinoma. The primary endpoint was ORR. Among Tms $(\mathrm{N}=7), 2$ PRs $(28.6 \%)$ and 5 SDs $(71.6 \%)$ were observed, with an ORR of $28.6 \%$, a DCR of $100 \%$ and a median duration of response (mDOR) that was not reached. In the TC group (26 patients), five patients had a PR (19.2\%) and 14 patients a SD (53.8\%), with an ORR of $19.2 \%$, a DCR of $73.1 \%$ and a mDOR of 9.7 months. After a median follow-up of 14.9 months, the median PFS was 6.1 months for both Tm (95\% CI: 4.3-7.9) and TC patients (95\% CI: 5.1-7.1) and the median OS was 14.5 months for $\mathrm{TC}$ and not reached for Tm patients.

Grade 3-4 irAEs were observed in $71.4 \%$ of Tm patients, the most common being myocarditis $(\mathrm{N}=3)$, hepatitis $(\mathrm{N}=2)$, thyroiditis $(\mathrm{N}=1)$, colitis $(\mathrm{N}=1)$ and nephritis $(\mathrm{N}=1)$. Among patients with TC, grade $3-4$ irAEs occurred in $15.4 \%$ of cases: hepatitis $(\mathrm{N}=2), \mathrm{MG}(\mathrm{N}=2)$ and subacute myoclonus $(\mathrm{N}=1)$. A patient with a $\mathrm{B} 2 \mathrm{Tm}$ treated with immunosuppressant therapy for a grade 4 autoimmune hepatitis, a grade 3 colitis and a grade 2 dermatitis, died because of superimposed cytomegalovirus infection. Three patients with pre-existing AD in their history developed severe irAEs. Considering the alarming incidence of severe irAEs, a study protocol amendment was emanated to exclude from the study patients with Tms and patients with a history of AD.

PD-L1 expression was evaluable in 24 patients and high expression ( $\geq 50 \%$ tumor proportion score) was observed in 14 tumors. Among tumors with high PD-L1 expression, five patients achieved a partial response while there was no response in the group with low PD-L1 expression $(p=0.034)$. There was no correlation between irAEs and high PD-L1 expression. Similarly, PD-L1 mRNA expression assessed using the nCounterPanCancer Immune Profiling Panel was higher in the four patients who responded compared to those who did not [80].

\section{Balancing between Efficacy and Toxicity of ICIs in TETs}

Immunotherapy showed an interesting antitumor activity in advanced pretreated TETs, partly comparable to what observed in other solid tumors $[36,42,47,76-78,80]$, so that pembrolizumab has been added as a second-line option for the treatment of patients with TC by the National Cancer Comprehensive Network (NCCN) guidelines [7]. Similar to what was observed in other cancers, a correlation between high PD-L1 expression and response to PD-1 blockade has been observed in TETs $[78,80]$.

Nevertheless, ICI studies in TET patients reported high rates of grade 3-4 irAEs, ranging from $13 \%$ to $38 \%$, even in patients with no previous history of $\mathrm{AD}$ or concurrent immune-related paraneoplastic syndrome. Interestingly, the development of irAEs has been associated with the response, as described in other malignancies, including non-small cell lung cancer and melanoma [56,58,77,78,81]. Most commonly reported grade 3-4 irAEs in TET trials were increased liver transaminases, myalgia, myositis, enteritis, myocarditis, thyroiditis, colitis and nephritis [76-78,80]. Multiple coexisting autoimmune adverse events were reported in many patients and required medical therapy and hospitalization, with fatal outcome for cardiac toxicity [55,82]. In one of the available phase II trials of pembrolizumab that enrolled both Tm and TC patients, severe adverse events were more commonly reported in Tm compared to TC patients ( $71.4 \%$ vs. $15.4 \%$, respectively) [80].

irAEs reported in TETs trials, such as musculoskeletal, neuromuscular and cardiac irAEs, are usually less common in other cancer types treated with the same agents, for a reported incidence of less than 1\% [53-55]. This can be due to the thymus function and the unique predisposition to immune paraneoplastic syndromes observed in TET patients, especially Tm ones $[16,83]$. Since PD-1/PD-L1 interaction plays a crucial role in the normal development of immune tolerance in peripheral lymphoid 
organs, it is therefore possible that ICIs could alter the mechanism of thymic epithelial cell death, cause loss of immune tolerance and eventually result in the development of a high rate of irAE [23].

In light of this, biomarkers are needed in order to identify both patients who are more likely to benefit from immunotherapy and those who are at risk of developing severe irAEs. Several potential response biomarkers have been evaluated, including PD-L1 expression on tumor cells, but also peripheral blood immune cells subsets, TCR sequencing, tumor immune infiltrate, HLA expression, expression profiles of genes involved in inflammation and specific genetic mutations [77,78,80]. Currently, PD-L1 expression is the only clinically validated predictive biomarker for ICIs targeting the PD-1/PD-L1 axis. PD-L1 expression on tumor cells is finely tuned at different levels by means of tumor intrinsic and extrinsic factors [84-86]. The role of CYLD in regulating PD-L1 expression has been recently investigated in TETs. CYLD, a tumor suppressor gene mutated in patients with familial cylindromatosis and in more than $10 \%$ of TCs, is a negative regulator of inflammation. Its loss of function determines an increase in PD-L1 expression, mediated by INF- $\gamma$ through the activation of the STAT1/IRF1 pathway [87]. Low expression of CYLD is associated with high PD-L1 expression, as observed also in the trial of pembrolizumab for TCs $[78,87]$.

On the other hand, predictors for toxicity still need to be identified: histology (Tm vs. TC), history of AD, PD-L1 expression, sex, ethnicity, mutational profile, TCR sequencing and HLA expression may have a role in predicting irAEs development on ICI $[77,78,80]$.

Furthermore, patients with pre-existing ADs are at high-risk of autoimmune flares [60,62]. This theoretically applies also to patients with immune-mediated paraneoplastic syndromes, such as TET ones. In this setting, strategies aimed at preventing ADs or immune-mediated paraneoplastic syndromes exacerbations as well as the development of severe irAEs in high-risk patients, like TET ones, are needed. However, to date no study or guideline addresses these issues. A multidisciplinary and personalized approach is thus necessary. As selective immunosuppressant seems not to affect ICI effectiveness while controlling autoimmune flares in patients with pre-existing ADs, this can be an option to be investigated, at least in high-risk patients, like TET patients, especially those with $\operatorname{Tm}[60]$.

\section{Future Perspectives: Ongoing Combination Trials of ICIs and Tyrosine Kinase Inhibitors (TKIs)}

As for other malignancies, there are high expectations in drugs under development for TETs, especially TKIs, ICIs and the combination of both, which are being investigated in many ongoing trials (Table 2).

Three phase II trials are currently ongoing to investigate in pre-treated patients the safety and clinical activity of avelumab in Tm or TC patients (NCT03076554), nivolumab in B3 Tm and TC patients (The NIVOTHYM trial, NCT03134118) and atezolizumab in TC patients (NCT04321330). Data from these trials of ICIs monotherapy are awaited to clarify the feasibility and the utility of ICI in TETs.

Combining ICI with ICIs or other immune-directed agents is an appealing strategy to increase the rate of responders and to improve outcomes. IDO1 is an intracellular enzyme that catalyzes the first and rate-limiting step of the tryptophan-kynurenine metabolism pathway, causing the cell-cycle arrest, effector T-cell apoptosis and determining local immunosuppression. IDO1 activation has been correlated with poor prognosis in several cancers [88]. The phase II trial of pembrolizumab in advanced TC (NCT02364076) has been amended to include an additional cohort of patients treated with pembrolizumab and epacadostat (an IDO1 inhibitor) on the basis of initial promising data in patients with melanoma and NSCLC [78]. Results are not available yet and recruitment has been halted after the failure of this combination in a large randomized phase III trial for advanced melanoma.

SO-C101 is a superagonist fusion protein of interleukin-15 (IL-15) and the IL-15 receptor $\alpha$ (IL-15R $\alpha$ ) that had shown to stimulate proliferation, differentiation and anti-tumor action of natural killers (NK) and CD8+ T-cells [89]. The phase I trial NCT04234113 is investigating the safety and 
tolerability of SO-C101 as monotherapy or in combination with pembrolizumab in patients with pre-treated advanced solid tumors, including TETs.

Table 2. Active and recruiting clinical trials of immune checkpoint inhibitor (ICI) monotherapy and combinations (source: clinicaltrials.gov; last accessed: 26 October 2020).

\begin{tabular}{lcccccc}
\hline Trial (NCT) & Phase & Disease & Setting & $\begin{array}{c}\text { Experimental } \\
\text { Drug }\end{array}$ & $\begin{array}{c}\text { Estimated } \\
\text { Enrolment }\end{array}$ & $\begin{array}{c}\text { Primary } \\
\text { Endpoint }\end{array}$ \\
\hline NCT03076554 & II & TC and Tm & $\begin{array}{c}\text { Pre-treated with } \\
\text { Platinum-based CHT }\end{array}$ & Avelumab & 55 & ORR, safety \\
\hline NCT03134118 & II & TC and Tm (B3) & $\begin{array}{c}\text { Pre-treated with } \\
\text { Platinum-based CHT }\end{array}$ & Nivolumab & 55 & $\begin{array}{c}\text { PFS at } 6 \\
\text { months }\end{array}$ \\
\hline NCT04321330 & II & TC & Pre-treated & Atezolizumab & 34 & ORR \\
\hline NCT04234113 & I/lb & $\begin{array}{c}\text { Solid tumors } \\
\text { including TETs }\end{array}$ & Pre-treated & $\begin{array}{c}\text { SO-C101 } \pm \\
\text { pembrolizumab }\end{array}$ & 96 & Safety \\
\hline NCT03463460 & II & TC & $\begin{array}{c}\text { Pre-treated with } \\
\text { Platinum-based CHT }\end{array}$ & $\begin{array}{c}\text { Pembrolizumab } \\
\text { and Sunitinib }\end{array}$ & 40 & ORR \\
\hline $\begin{array}{c}\text { NCT03583086 } \\
\text { I/II }\end{array}$ & $\begin{array}{c}\text { Thoracic tumors } \\
\text { including TC }\end{array}$ & Pre-treated & $\begin{array}{c}\text { Vorolanib and } \\
\text { nivolumab }\end{array}$ & 177 & $\begin{array}{c}\text { Safety and } \\
\text { ORR }\end{array}$ \\
\hline $\begin{array}{c}\text { 2017-004048-38 } \\
\text { study) }\end{array}$ & II & TC and Tm (B3) & $\begin{array}{c}\text { Pre-treated with } \\
\text { Platinum-based CHT }\end{array}$ & $\begin{array}{c}\text { Avelumab and } \\
\text { Axitinib }\end{array}$ & 33 & ORR \\
\hline
\end{tabular}

IO: immuno-oncology; TC: thymic carcinoma; Tm: thymoma; CHT: chemotherapy, ORR: overall response rate. * EUDRACT trial registration number.

Targeted therapy with TKI is a promising treatment for TETs, given good efficacy and the manageable safety profile. As TKIs are characterized by a shorter time to response and a higher response rate compared to ICIs, ICIs show a prolonged benefit in those who respond to treatment $[77,78,80,90,91]$. The combination of an ICI and a TKI is an appealing strategy that could provide patients the benefits of both strategies, but also increase toxicity. The phase II trial NCT03463460, testing the combination of pembrolizumab and sunitinib is currently ongoing in refractory metastatic or unresectable TC patients. The primary endpoint of the trial is the activity of the treatment measured by ORR, while the secondary endpoints are the incidence of irAEs, PFS and OS. Furthermore, the study aims at exploring a possible correlation between clinical benefit and PD-L1 expression level and to investigate whether sunitinib could affect PD-L1 expression, and the number of tumor-infiltrating lymphocytes and of myeloid-derived suppressor cells in the tumor and peripheral blood. Another phase I/II trial (NCT03583086) is a dose escalation and dose expansion study of vorolanib, an oral VEGFR/PDGFR kinase inhibitor, in combination with nivolumab in patients with refractory thoracic malignancies, including TC patients. The endpoint for the phase I part of the study is assessing the safety and tolerability of the combination, while the primary endpoint of the phase II part is to evaluate the efficacy, by measuring ORR. In addition, an explorative analysis will assess the correlation of PD-L1 expression and TMB with the experimental treatment. Finally, the preliminary results of the phase II CAVEATT study have been recently published: 1 patient with B3 Tm and 12 with TCs in progression after at least one line of platinum-based chemotherapy were enrolled and treated with avelumab in combination with axitinib, an oral VEGFR-1/2/3 kinase inhibitor. $40 \%$ of patients had a $\mathrm{PR}, 60 \%$ a SD with a mPFS of 7.9 months. G3-4 AEs were reported in two patients and were attributable to axitinib (hypertension and hand-foot syndrome), while no irAEs were described. The trial accrual is currently ongoing [92].

\section{Conclusions}

The thymus has a unique role in the development of adaptive immunity fostering the maturation of T-cells through the proper selection of non-self-reactive clones. Due to this, treatment with ICIs is associated with a high rate of irAEs in TET patients, so that, to date, chemotherapy still represents the 
backbone of systemic treatment for these patients. Available data do not support the use of ICIs in TET patients outside of clinical trials, especially in patients with Tms and autoimmune paraneoplastic syndromes, because of the high risk for severe irAEs. However, TC showed higher response rates with lower rates of irAEs compared to Tms. The latter is however still higher than what was observed in other solid tumors. The identification of factors to predict response and/or the development of irAEs in TET patients (e.g., Tm vs. TC, PD-L1 expression, TMB, HLA, PBMC and T-cell receptor density among others) could help in weighing risks and benefits and guide the choice of active treatments (ICI vs. chemotherapy/TKI) and prevention immunosuppressive strategies, once validated.

Author Contributions: Conceptualization: G.L., V.T., L.M., and A.D.G.; Writing-Original Draft Preparation: V.T. and L.M.; Figures and Tables: V.T., L.M., C.P.; Writing-Review and Editing: V.T., L.M., A.D.G., C.P., G.L., D.C., M.A.P.; Supervision: G.L. and M.A.P. All authors have read and agreed to the published version of the manuscript.

Funding: This research received no external funding.

Conflicts of Interest: The authors declare no conflict of interest.

\section{References}

1. RARECARENet. Available online: www.rarecarenet.eu (accessed on 26 November 2020).

2. Marx, A.; Chan, J.K.C.; Coindre, J.-M.; Detterbeck, F.; Girard, N.; Harris, N.L.; Jaffe, E.S.; Kurrer, M.O.; Marom, E.M.; Moreira, A.L.; et al. The 2015 World Health Organization Classification of Tumors of the Thymus: Continuity and Changes. J. Thorac. Oncol. Off. Publ. Int. Assoc. Study Lung Cancer 2015, 10, 1383-1395. [CrossRef] [PubMed]

3. Marx, A.; Ströbel, P.; Badve, S.S.; Chalabreysse, L.; Chan, J.K.C.; Chen, G.; De Leval, L.; Detterbeck, F.; Girard, N.; Huang, J.; et al. ITMIG consensus statement on the use of the WHO histological classification of thymoma and thymic carcinoma: Refined definitions, histological criteria, and reporting. J. Thorac. Oncol. Off. Publ. Int. Assoc. Study Lung Cancer 2014, 9, 596-611. [CrossRef] [PubMed]

4. Girard, N.; Ruffini, E.; Marx, A.; Faivre-Finn, C.; Peters, S. Thymic epithelial tumours: ESMO Clinical Practice Guidelines for diagnosis, treatment and follow-up. Ann. Oncol. 2015, 26, v40-v55. [CrossRef] [PubMed]

5. Carter, B.W.; Benveniste, M.F.; Madan, R.; Godoy, M.C.; De Groot, P.M.; Truong, M.T.; Rosado-de-Christenson, M.L.; Marom, E.M. IASLC/ITMIG Staging System and Lymph Node Map for Thymic Epithelial Neoplasms. Radiogr Rev. Publ. Radiol Soc. N. Am. Inc. 2017, 37, 758-776. [CrossRef] [PubMed]

6. Imbimbo, M.; Ottaviano, M.; Vitali, M.; Fabbri, A.; Leuzzi, G.; Fiore, M.; Franceschini, D.; Pasello, G.; Perrino, M.; Schiavon, M.; et al. Best practices for the management of thymic epithelial tumors: A position paper by the Italian collaborative group for ThYmic MalignanciEs (TYME). Cancer Treat Rev. 2018, 71, 76-87. [CrossRef] [PubMed]

7. $\quad$ Ettinger, D.S.; Wood, D.E.; Aggarwal, C.; Aisner, D.L.; Akerley, W.; Bauman, J.R.; Bharat, A.; Bruno, D.S.; Chang, J.Y.; Chirieac, L.R.; et al. Thymomas and Thymic Carcinomas, NCCN Guidelines, Version 1. 2020-27 November 2019. Available online: www.nccn.org (accessed on 26 November 2020).

8. Chen, G.; Marx, A.; Chen, W.-H.; Yong, J.; Puppe, B.; Stroebel, P.; Mueller-Hermelink, H.K. New WHO histologic classification predicts prognosis of thymic epithelial tumors: A clinicopathologic study of 200 thymoma cases from China. Cancer 2002, 95, 420-429. [CrossRef]

9. Hamaji, M. The role of adjuvant chemotherapy following resection of early stage thymoma. Ann. Cardiothorac. Surg. 2016, 5, 45-50. [CrossRef]

10. Komaki, R.; Gomez, D.R. Radiotherapy for thymic carcinoma: Adjuvant, inductive, and definitive. Front. Oncol. 2014, 3, 330. [CrossRef]

11. Loehrer, P.J.S.; Kim, K.; Aisner, S.C.; Livingston, R.; Einhorn, L.H.; Johnson, D.; Blum, R. Cisplatin plus doxorubicin plus cyclophosphamide in metastatic or recurrent thymoma: Final results of an intergroup trial. The Eastern Cooperative Oncology Group, Southwest Oncology Group, and Southeastern Cancer Study Group. J. Clin. Oncol. Off. J. Am. Soc. Clin. Oncol. 1994, 12, 1164-1168. [CrossRef]

12. Lemma, G.L.; Lee, J.-W.; Aisner, S.C.; Langer, C.J.; Tester, W.J.; Johnson, D.H.; Loehrer, P.J.S. Phase II study of carboplatin and paclitaxel in advanced thymoma and thymic carcinoma. J. Clin. Oncol. Off. J. Am. Soc. Clin. Oncol. 2011, 29, 2060-2065. [CrossRef] 
13. Gökmen-Polar, Y.; Cook, R.W.; Goswami, C.P.; Wilkinson, J.; Maetzold, D.; Stone, J.F.; Oelschlager, K.M.; Vladislav, I.T.; Shirar, K.L.; Kesler, K.A.; et al. A gene signature to determine metastatic behavior in thymomas. PLOS ONE 2013, 8, e66047. [CrossRef] [PubMed]

14. Detterbeck, F.; Youssef, S.; Ruffini, E.; Okumura, M. A review of prognostic factors in thymic malignancies. J. Thorac. Oncol. Off. Publ. Int. Assoc. Study Lung Cancer 2011, 6 (Suppl. 3), S1698-S1704. [CrossRef] [PubMed]

15. Bedekovics, J.; Beke, L.; Mokanszki, A.; Szilagyi, S.; Mehes, G. Programmed Death-ligand 1 (PD-L1) Expression in Thymic Epithelial Tumors. Appl. Immunohistochem. Mol. Morphol. AIMM 2020, 28, 1-9. [CrossRef] [PubMed]

16. Radovich, M.; Pickering, C.R.; Felau, I.; Ha, G.; Zhang, H.; Jo, H.; Hoadley, K.A.; Anur, P.; Zhang, J.; McLellan, M.; et al. The Integrated Genomic Landscape of Thymic Epithelial Tumors. Cancer Cell 2018, 33, 244-258. [CrossRef]

17. Borley, N.R.; Collins, P.; Crossman, A.R.; Gatzoulis, M.A.; Healy, J.C.; Johnson, D.; Mahadevan, V.; Richard, L.M.; Wigley, C.B. Gray's Anatomy. The Anatomical Basis of Clinical Practice, 40th ed.; Standring, S., Ed.; Elsevier: Amsterdam, The Netherlands, 2008.

18. Nishimura, H.; Honjo, T.; Minato, N. Facilitation of beta selection and modification of positive selection in the thymus of PD-1-deficient mice. J. Exp. Med. 2000, 191, 891-898. [CrossRef]

19. Mathis, D.; Benoist, C. A decade of AIRE. Nat. Rev. Immunol. 2007, 7, 645-650. [CrossRef]

20. Anderson, M.S.; Su, M.A. AIRE expands: New roles in immune tolerance and beyond. Nat. Rev. Immunol. 2016, 16, 247-258. [CrossRef]

21. Takaba, H.; Takayanagi, H. The Mechanisms of T Cell Selection in the Thymus. Trends Immunol. 2017, 38, 805-816. [CrossRef]

22. Iberg, C.A.; Jones, A.; Hawiger, D. Dendritic Cells as Inducers of Peripheral Tolerance. Trends Immunol. 2017, 38, 793-804. [CrossRef]

23. Francisco, L.M.; Sage, P.T.; Sharpe, A.H. The PD-1 pathway in tolerance and autoimmunity. Immunol. Rev. 2010, 236, 219-242. [CrossRef]

24. Padda, S.K.; Yao, X.; Antonicelli, A.; Riess, J.W.; Shang, Y.; Shrager, J.B.; Korst, R.; Detterbeck, F.; Huang, J.; Burt, B.M.; et al. Paraneoplastic Syndromes and Thymic Malignancies: An Examination of the International Thymic Malignancy Interest Group Retrospective Database. J. Thorac. Oncol. Off. Publ. Int. Assoc. Study Lung Cancer 2018, 13, 436-446. [CrossRef] [PubMed]

25. Tormoehlen, L.M.; Pascuzzi, R.M. Thymoma, myasthenia gravis, and other paraneoplastic syndromes. Hematol. Oncol. Clin. N. Am. 2008, 22, 509-526. [CrossRef] [PubMed]

26. Rashid, O.M.; Cassano, A.D.; Takabe, K. Thymic neoplasm: A rare disease with a complex clinical presentation. J. Thorac. Dis. 2013, 5, 173-183. [CrossRef] [PubMed]

27. Gilhus, N.E. Myasthenia Gravis. N. Engl. J. Med. 2016, 375, 2570-2581. [CrossRef]

28. Comacchio, G.M.; Marulli, G.; Mammana, M.; Natale, G.; Schiavon, M.; Rea, F. Surgical Decision Making: Thymoma and Myasthenia Gravis. Thorac. Surg Clin. 2019, 29, 203-213. [CrossRef]

29. Yokoyama, S.; Miyoshi, H. Thymic tumors and immune checkpoint inhibitors. J. Thorac. Dis. 2018, 10 (Suppl. 13), S1509-S1515. [CrossRef]

30. Liu, Y.; Zhang, H.; Zhang, P.; Meng, F.; Chen, Y.; Wang, Y.; Yao, Y.; Qi, B. Autoimmune regulator expression in thymomas with or without autoimmune disease. Immunol. Lett. 2014, 161, 50-56. [CrossRef]

31. Hoffacker, V.; Schultz, A.; Tiesinga, J.J.; Gold, R.; Schalke, B.; Nix, W.; Kiefer, R.; Müller-Hermelink, H.K.; Marx, A. Thymomas alter the T-cell subset composition in the blood: A potential mechanism for thymoma-associated autoimmune disease. Blood 2000, 96, 3872-3879. [CrossRef]

32. Lee, M.-C.; Hsiao, T.-H.; Chuang, H.-N.; Lee, L.-W.; Chi, P.-L.; Tsai, H.-M.; Mao, C.-L.; Hsu, C.-P. Molecular profiling of thymoma with myasthenia gravis: Risk factors of developing myasthenia gravis in thymoma patients. Lung Cancer 2020, 139, 157-164. [CrossRef]

33. Mellman, I.; Coukos, G.; Dranoff, G. Cancer immunotherapy comes of age. Nature 2011, 480, 480-489. [CrossRef]

34. Schadendorf, D.; Hodi, F.S.; Robert, C.; Weber, J.S.; Margolin, K.; Hamid, O.; Patt, D.; Chen, T.-T.; Berman, D.M.; Wolchok, J.D. Pooled Analysis of Long-Term Survival Data From Phase II and Phase III Trials of Ipilimumab in Unresectable or Metastatic Melanoma. J. Clin. Oncol. Off. J. Am. Soc. Clin. Oncol. 2015, 33, 1889-1894. [CrossRef] [PubMed] 
35. Ascierto, P.A.; Long, G.V.; Robert, C.; Brady, B.; Dutriaux, C.; Di Giacomo, A.M.; Mortier, L.; Hassel, J.C.; Rutkowski, P.; McNeil, C.; et al. Survival Outcomes in Patients With Previously Untreated BRAF Wild-Type Advanced Melanoma Treated With Nivolumab Therapy: Three-Year Follow-up of a Randomized Phase 3 Trial. JAMA Oncol. 2019, 5, 187-194. [CrossRef] [PubMed]

36. Borghaei, H.; Paz-Ares, L.; Horn, L.; Spigel, D.R.; Steins, M.; Ready, N.E.; Chow, L.Q.; Vokes, E.E.; Felip, E.; Holgado, E.; et al. Nivolumab versus Docetaxel in Advanced Nonsquamous Non-Small-Cell Lung Cancer. N. Engl. J. Med. 2015, 373, 1627-1639. [CrossRef] [PubMed]

37. Andre, T.; Shiu, K.-K.; Kim, T.W.; Jensen, B.V.; Jensen, L.H.; Punt, C.J.A.; Smith, D.M.; Garcia-Carbonero, R.; Benavides, M.; Gibbs, P.; et al. Pembrolizumab versus chemotherapy for microsatellite instability-high/mismatch repair deficient metastatic colorectal cancer: The phase 3 KEYNOTE-177 Study. J. Clin. Oncol. 2020, 38, LBA4. [CrossRef]

38. Horn, L.; Mansfield, A.S.; Szczęsna, A.; Havel, L.; Krzakowski, M.; Hochmair, M.J.; Huemer, F.; Losonczy, G.; Johnson, M.L.; Nishio, M.; et al. First-Line Atezolizumab plus Chemotherapy in Extensive-Stage Small-Cell Lung Cancer. N. Engl. J. Med. 2018, 379, 2220-2229. [CrossRef]

39. Schmid, P.; Adams, S.; Rugo, H.S.; Schneeweiss, A.; Barrios, C.H.; Iwata, H.; Diéras, V.; Hegg, R.; Im, S.-A.; Shaw Wright, G.; et al. Atezolizumab and Nab-Paclitaxel in Advanced Triple-Negative Breast Cancer. N. Engl. J. Med. 2018, 379, 2108-2121. [CrossRef]

40. Larkin, J.; Chiarion-Sileni, V.; Gonzalez, R.; Grob, J.-J.; Rutkowski, P.; Lao, C.D.; Cowey, C.L.; Schadendorf, D.; Wagstaff, J.; Dummer, R.; et al. Five-Year Survival with Combined Nivolumab and Ipilimumab in Advanced Melanoma. N. Engl. J. Med. 2019, 381, 1535-1546. [CrossRef]

41. Reck, M.; Rodríguez-Abreu, D.; Robinson, A.G.; Hui, R.; Csőszi, T.; Fülöp, A.; Gottfried, M.; Peled, N.; Tafreshi, A.; Cuffe, S.; et al. Updated Analysis of KEYNOTE-024: Pembrolizumab Versus Platinum-Based Chemotherapy for Advanced Non-Small-Cell Lung Cancer With PD-L1 Tumor Proportion Score of 50\% or Greater. J. Clin. Oncol. 2019, 37, 537-546. [CrossRef]

42. Hodi, F.S.; O’Day, S.J.; McDermott, D.F.; Weber, R.W.; Sosman, J.A.; Haanen, J.B.; Gonzalez, R.; Robert, C.; Schadendorf, D.; Hassel, J.C.; et al. Improved Survival with Ipilimumab in Patients with Metastatic Melanoma. N. Engl. J. Med. 2010, 363, 711-723. [CrossRef]

43. Robert, C.; Long, G.V.; Brady, B.; Dutriaux, C.; Maio, M.; Mortier, L.; Hassel, J.C.; Rutkowski, P.; McNeil, C.; Kalinka-Warzocha, E.; et al. Nivolumab in previously untreated melanoma without BRAF mutation. N. Engl. J. Med. 2015, 372, 320-330. [CrossRef]

44. Larkin, J.; Chiarion-Sileni, V.; Gonzalez, R.; Grob, J.J.; Cowey, C.L.; Lao, C.D.; Schadendorf, D.; Dummer, R.; Smylie, M.; Rutkowski, P.; et al. Combined Nivolumab and Ipilimumab or Monotherapy in Untreated Melanoma. N. Engl. J. Med. 2015, 373, 23-34. [CrossRef] [PubMed]

45. Robert, C.; Schachter, J.; Long, G.V.; Arance, A.; Grob, J.J.; Mortier, L.; Daud, A.; Carlino, M.S.; McNeil, C.; Lotem, M.; et al. Pembrolizumab versus Ipilimumab in Advanced Melanoma. N. Engl. J. Med. 2015, 372, 2521-2532. [CrossRef] [PubMed]

46. Reck, M.; Rodríguez-Abreu, D.; Robinson, A.G.; Hui, R.; Csőszi, T.; Fülöp, A.; Gottfried, M.; Peled, N.; Tafreshi, A.; Cuffe, S.; et al. Pembrolizumab versus Chemotherapy for PD-L1-Positive Non-Small-Cell Lung Cancer. N. Engl. J. Med. 2016, 375, 1823-1833. [CrossRef] [PubMed]

47. Brahmer, J.; Reckamp, K.L.; Baas, P.; Crinò, L.; Eberhardt, W.E.E.; Poddubskaya, E.; Antonia, S.; Pluzanski, A.; Vokes, E.E.; Holgado, E.; et al. Nivolumab versus Docetaxel in Advanced Squamous-Cell Non-Small-Cell Lung Cancer. N. Engl. J. Med. 2015, 373, 123-135. [CrossRef] [PubMed]

48. Gibney, G.T.; Weiner, L.M.; Atkins, M.B. Predictive biomarkers for checkpoint inhibitor-based immunotherapy. Lancet Oncol. 2016, 17, e542-e551. [CrossRef]

49. Teng, F.; Meng, X.; Kong, L.; Yu, J. Progress and challenges of predictive biomarkers of anti PD-1/PD-L1 immunotherapy: A systematic review. Cancer Lett. 2018, 414, 166-173. [CrossRef]

50. Gelsomino, F.; Lamberti, G.; Parisi, C.; Casolari, L.; Melotti, B.; Sperandi, F.; Ardizzoni, A. The evolving landscape of immunotherapy in small-cell lung cancer: A focus on predictive biomarkers. Cancer Treat Rev. 2019, 79, 101887. [CrossRef]

51. Le, D.T.; Durham, J.N.; Smith, K.N.; Wang, H.; Bartlett, B.R.; Aulakh, L.K.; Lu, S.; Kemberling, H.; Wilt, C.; Luber, B.S.; et al. Mismatch repair deficiency predicts response of solid tumors to PD-1 blockade. Science 2017, 357, 409-413. [CrossRef] 
52. Wang, Y.; Zhou, S.; Yang, F.; Qi, X.; Wang, X.; Guan, X.; Shen, C.; Duma, N.; Vera Aguilera, J.; Chintakuntlawar, A.; et al. Treatment-Related Adverse Events of PD-1 and PD-L1 Inhibitors in Clinical Trials. JAMA Oncol. 2019, 5, 1008. [CrossRef]

53. Wang, D.Y.; Salem, J.-E.; Cohen, J.V.; Chandra, S.; Menzer, C.; Ye, F.; Zhao, S.; Das, S.; Beckermann, K.E.; Ha, L.; et al. Fatal Toxic Effects Associated With Immune Checkpoint Inhibitors: A Systematic Review and Meta-analysis. JAMA Oncol. 2018, 4, 1721-1728. [CrossRef]

54. Xu, C.; Chen, Y.-P.; Du, X.-J.; Liu, J.-Q.; Huang, C.-L.; Chen, L.; Zhou, G.-Q.; Li, W.-F.; Mao, Y.-P.; Hsu, C.; et al. Comparative safety of immune checkpoint inhibitors in cancer: Systematic review and network meta-analysis. BMJ 2018, 363, k4226. [CrossRef] [PubMed]

55. Johnson, D.B.; Balko, J.M.; Compton, M.L.; Chalkias, S.; Gorham, J.; Xu, Y.; Hicks, M.; Puzanov, I.; Alexander, M.R.; Bloomer, T.L.; et al. Fulminant Myocarditis with Combination Immune Checkpoint Blockade. N. Engl. J. Med. 2016, 375, 1749-1755. [CrossRef] [PubMed]

56. Ricciuti, B.; Naqash, A.R.; Naidoo, J.; Sehgal, K.; Miller, A.; Kehl, K.; Venkatraman, D.; Sands, J.; Lamberti, G.; Recondo, G.; et al. Association between immune-related adverse events and clinical outcomes to PD-1/PD-L1 blockade in small cell lung cancer. JTO Clin. Res. Rep. 2020, 100074. [CrossRef]

57. Naqash, A.R.; Ricciuti, B.; Owen, D.H.; Florou, V.; Toi, Y.; Cherry, C.; Hafiz, M.; De Giglio, A.; Muzaffar, M.; Patel, S.H.; et al. Outcomes associated with immune-related adverse events in metastatic non-small cell lung cancer treated with nivolumab: A pooled exploratory analysis from a global cohort. Cancer Immunol. Immunother. 2020, 69, 1177-1187. [CrossRef] [PubMed]

58. Ricciuti, B.; Genova, C.; De Giglio, A.; Bassanelli, M.; Dal Bello, M.G.; Metro, G.; Brambilla, M.; Baglivo, S.; Grossi, F.; Chiari, R. Impact of immune-related adverse events on survival in patients with advanced non-small cell lung cancer treated with nivolumab: Long-term outcomes from a multi-institutional analysis. J. Cancer Res. Clin. Oncol. 2019, 145, 479-485. [CrossRef] [PubMed]

59. Teulings, H.-E.; Limpens, J.; Jansen, S.N.; Zwinderman, A.H.; Reitsma, J.B.; Spuls, P.I.; Luiten, R.M. Vitiligo-Like Depigmentation in Patients With Stage III-IV Melanoma Receiving Immunotherapy and Its Association With Survival: A Systematic Review and Meta-Analysis. J. Clin. Oncol. 2015, 33, 773-781. [CrossRef]

60. Haanen, J.; Ernstoff, M.S.; Wang, Y.; Menzies, A.M.; Puzanov, I.; Grivas, P.; Larkin, J.; Peters, S.; Thompson, J.A.; Obeid, M. Autoimmune diseases and immune-checkpoint inhibitors for cancer therapy: Review of the literature and personalized risk-based prevention strategy. Ann. Oncol. 2020, 31, 724-744. [CrossRef]

61. Leonardi, G.C.; Gainor, J.F.; Altan, M.; Kravets, S.; Dahlberg, S.E.; Gedmintas, L.; Azimi, R.; Rizvi, H.; Riess, J.W.; Hellmann, M.D.; et al. Safety of programmed death-1 pathway inhibitors among patients with non-small-cell lung cancer and preexisting autoimmune disorders. J Clin. Oncol. 2018, 36, 1905-1912. [CrossRef]

62. Abu-Sbeih, H.; Faleck, D.M.; Ricciuti, B.; Mendelsohn, R.B.; Naqash, A.R.; Cohen, J.V.; Sellers, M.C.; Balaji, A.; Ben-Betzalel, G.; Hajir, I.; et al. Immune Checkpoint Inhibitor Therapy in Patients With Preexisting Inflammatory Bowel Disease. Am. J. Gastroenterol. 2019, 114, S451. [CrossRef]

63. Frohne, C.C.; Llano, E.M.; Perkovic, A.; Cohen, R.D.; Luke, J.J. Complete response of metastatic melanoma in a patient with Crohn's disease simultaneously receiving anti- $\alpha 4 \beta 7$ and anti-PD1 antibodies. J. Immunother. Cancer 2019, 7, 1. [CrossRef]

64. Uemura, M.; Trinh, V.A.; Haymaker, C.; Jackson, N.; Kim, D.W.; Allison, J.P.; Sharma, P.; Vence, L.; Bernatchez, C.; Hwu, P.; et al. Selective inhibition of autoimmune exacerbation while preserving the anti-tumor clinical benefit using IL-6 blockade in a patient with advanced melanoma and Crohn's disease: A case report. J. Hematol. Oncol. 2016, 9, 81. [CrossRef] [PubMed]

65. Menzies, A.M.; Johnson, D.B.; Ramanujam, S.; Atkinson, V.G.; Wong, A.N.M.; Park, J.J.; McQuade, J.L.; Shoushtari, A.N.; Tsai, K.K.; Eroglu, Z.; et al. Anti-PD-1 therapy in patients with advanced melanoma and preexisting autoimmune disorders or major toxicity with ipilimumab. Ann. Oncol. Off. J. Eur. Soc. Med. Oncol. 2017, 28, 368-376. [CrossRef] [PubMed]

66. Ricciuti, B.; Dahlberg, S.E.; Adeni, A.; Sholl, L.M.; Nishino, M.; Awad, M.M. Immune checkpoint inhibitor outcomes for patients with non-small-cell lung cancer receiving baseline corticosteroids for palliative versus nonpalliative indications. J. Clin. Oncol. 2019, 37, 1927-1934. [CrossRef] [PubMed] 
67. Spranger, S.; Spaapen, R.M.; Zha, Y.; Williams, J.; Meng, Y.; Ha, T.T.; Gajewski, T.F. Up-regulation of PD-L1, IDO, and T(regs) in the melanoma tumor microenvironment is driven by CD8(+) T cells. Sci. Transl. Med. 2013, 5, 200ra116. [CrossRef] [PubMed]

68. Katsuya, Y.; Fujita, Y.; Horinouchi, H.; Ohe, Y.; Watanabe, S.-I.; Tsuta, K. Immunohistochemical status of PD-L1 in thymoma and thymic carcinoma. Lung Cancer 2015, 88, 154-159. [CrossRef] [PubMed]

69. Rouquette, I.; Taranchon-Clermont, E.; Gilhodes, J.; Bluthgen, M.-V.; Perallon, R.; Chalabreysse, L.; De Muret, A.; Hofman, V.; Marx, A.; Parrens, M.; et al. Immune biomarkers in thymic epithelial tumors: Expression patterns, prognostic value and comparison of diagnostic tests for PD-L1. Biomark Res. 2019, 7, 28. [CrossRef]

70. Owen, D.; Chu, B.; Lehman, A.M.; Annamalai, L.; Yearley, J.H.; Shilo, K.; Otterson, G.A. Expression Patterns, Prognostic Value, and Intratumoral Heterogeneity of PD-L1 and PD-1 in Thymoma and Thymic Carcinoma. J. Thorac. Oncol. Off. Publ. Int. Assoc. Study Lung Cancer 2018, 13, 1204-1212. [CrossRef]

71. Tiseo, M.; Damato, A.; Longo, L.; Barbieri, F.; Bertolini, F.; Stefani, A.; Migaldi, M.; Gnetti, L.; Camisa, R.; Bordi, P.; et al. Analysis of a panel of druggable gene mutations and of ALK and PD-L1 expression in a series of thymic epithelial tumors (TETs). Lung Cancer 2017, 104, 24-30. [CrossRef]

72. Yokoyama, S.; Miyoshi, H.; Nakashima, K.; Shimono, J.; Hashiguchi, T.; Mitsuoka, M.; Takamori, S.; Akagi, Y.; Ohshima, K. Prognostic Value of Programmed Death Ligand 1 and Programmed Death 1 Expression in Thymic Carcinoma. Clin. Cancer Res. Off. J. Am Assoc. Cancer Res. 2016, 22, 4727-4734. [CrossRef]

73. Wei, Y.-F.; Chu, C.-Y.; Chang, C.-C.; Lin, S.-H.; Su, W.-C.; Tseng, Y.-L.; Lin, C.-C.; Yen, Y.-T. Different pattern of PD-L1, IDO, and FOXP3 Tregs expression with survival in thymoma and thymic carcinoma. Lung Cancer 2018, 125, 35-42. [CrossRef]

74. Wang, Y.; Thomas, A.; Lau, C.; Rajan, A.; Zhu, Y.; Killian, J.K.; Petrini, I.; Pham, T.; Morrow, B.; Zhong, X.; et al. Mutations of epigenetic regulatory genes are common in thymic carcinomas. Sci. Rep. 2014, 4, 7336. [CrossRef] [PubMed]

75. Petrini, I.; Meltzer, P.S.; Kim, I.-K.; Lucchi, M.; Park, K.-S.; Fontanini, G.; Gao, J.; Zucali, P.A.; Calabrese, F.; Favaretto, A.; et al. A specific missense mutation in GTF2I occurs at high frequency in thymic epithelial tumors. Nat. Genet. 2014, 46, 844-849. [CrossRef] [PubMed]

76. Katsuya, Y.; Horinouchi, H.; Seto, T.; Umemura, S.; Hosomi, Y.; Satouchi, M.; Nishio, M.; Kozuki, T.; Hida, T.; Sukigara, T.; et al. Single-arm, multicentre, phase II trial of nivolumab for unresectable or recurrent thymic carcinoma: PRIMER study. Eur. J Cancer 2019, 113, 78-86. [CrossRef] [PubMed]

77. Rajan, A.; Heery, C.R.; Thomas, A.; Mammen, A.L.; Perry, S.; O’Sullivan Coyne, G.; Guha, U.; Berman, A.; Szabo, E.; Madan, R.A.; et al. Efficacy and tolerability of anti-programmed death-ligand 1 (PD-L1) antibody (Avelumab) treatment in advanced thymoma. J. Immunother. Cancer 2019, 7, 269. [CrossRef]

78. Giaccone, G.; Kim, C.; Thompson, J.; McGuire, C.; Kallakury, B.; Chahine, J.J.; Manning, M.; Mogg, R.; Blumenschein, W.M.; Tan, M.T.; et al. Pembrolizumab in patients with thymic carcinoma: A single-arm, single-centre, phase 2 study. Lancet Oncol. 2018, 19, 347-355. [CrossRef]

79. Kim, I.-K.; Rao, G.; Zhao, X.; Fan, R.; Avantaggiati, M.L.; Wang, Y.; Zhang, Y.-W.; Giaccone, G. Mutant GTF2I induces cell transformation and metabolic alterations in thymic epithelial cells. Cell Death Differ. 2020, 27, 2263-2279. [CrossRef]

80. Cho, J.; Kim, H.S.; Ku, B.M.; Choi, Y.-L.; Cristescu, R.; Han, J.; Sun, J.-M.; Lee, S.-H.; Ahn, J.S.; Park, K.; et al. Pembrolizumab for Patients With Refractory or Relapsed Thymic Epithelial Tumor: An Open-Label Phase II Trial. J. Clin. Oncol. Off. J. Am. Soc. Clin. Oncol. 2019, 37, 2162-2170. [CrossRef]

81. Indini, A.; Di Guardo, L.; Cimminiello, C.; Prisciandaro, M.; Randon, G.; De Braud, F.; Del Vecchio, M. Immune-related adverse events correlate with improved survival in patients undergoing anti-PD1 immunotherapy for metastatic melanoma. J. Cancer Res. Clin. Oncol. 2019, 145, 511-521. [CrossRef]

82. Thomas, A.; Rajan, A.; Berman, A.; Giaccone, G. Multiorgan autoimmune manifestations associated with thymoma. J. Thorac. Oncol. Off. Publ. Int. Assoc. Study Lung Cancer 2015, 10, e5-e7. [CrossRef]

83. Lippner, E.A.; Lewis, D.B.; Robinson, W.H.; Katsumoto, T.R. Paraneoplastic and Therapy-Related Immune Complications in Thymic Malignancies. Curr. Treat. Options Oncol. 2019, 20, 62. [CrossRef]

84. Lamberti, G.; Sisi, M.; Andrini, E.; Palladini, A.; Giunchi, F.; Lollini, P.; Ardizzoni, A.; Gelsomino, F. The Mechanisms of PD-L1 Regulation in Non-Small-Cell Lung Cancer (NSCLC): Which Are the Involved Players? Cancers 2020, 12, 3129. [CrossRef] [PubMed] 
85. Shen, X.; Zhang, L.; Li, J.; Li, Y.; Wang, Y.; Xu, Z.X. Recent findings in the regulation of programmed death ligand 1 expression. Front. Immunol. 2019, 10, 1-25. [CrossRef] [PubMed]

86. Wang, Y.; Wang, H.; Yao, H.; Li, C.; Fang, J.-Y.; Xu, J. Regulation of PD-L1: Emerging Routes for Targeting Tumor Immune Evasion. Front. Pharmacol. 2018, 9, 536. [CrossRef] [PubMed]

87. Umemura, S.; Zhu, J.; Chahine, J.J.; Kallakury, B.; Chen, V.; Kim, I.-K.; Zhang, Y.-W.; Goto, K.; He, Y.; Giaccone, G. Downregulation of CYLD promotes IFN- $\gamma$ mediated PD-L1 expression in thymic epithelial tumors. Lung Cancer 2020, 147, 221-228. [CrossRef]

88. Munn, D.H.; Mellor, A.L. Indoleamine 2,3-dioxygenase and tumor-induced tolerance. J. Clin. Investig. 2007, 117, 1147-1154. [CrossRef]

89. Guo, Y.; Luan, L.; Patil, N.K.; Sherwood, E.R. Immunobiology of the IL-15/IL-15R $\alpha$ complex as an antitumor and antiviral agent. Cytokine Growth Factor Rev. 2017, 38, 10-21. [CrossRef]

90. Thomas, A.; Rajan, A.; Berman, A.; Tomita, Y.; Brzezniak, C.; Lee, M.-J.; Lee, S.; Ling, A.; Spittler, A.J.; Carter, C.A.; et al. Sunitinib in patients with chemotherapy-refractory thymoma and thymic carcinoma: An open-label phase 2 trial. Lancet Oncol. 2015, 16, 177-186. [CrossRef]

91. Itoh, S.; Satouchi, M.; Sato, J.; Okuma, Y.; Niho, S.; Mizugaki, H.; Murakami, H.; Fujisaka, Y.; Kozuki, T.; Nakamura, K.; et al. Durable anti-tumor activity of the multi-targeted inhibitor lenvatinib in patients with advanced or metastatic thymic carcinoma: Preliminary results from a multicenter phase II (REMORA) trial. Ann. Oncol. 2019, 30, v748-v749. [CrossRef]

92. Conforti, F.; Pala, L.; Catania, C.; Zucali, P.A.; Della Vigna, P.; Pirola, S.; Stucchi, S.; Pennacchioli, E.; Queirolo, P.; Giaccone, G.; et al. Safety and activity of Combined AVElumab with Axitinib in unresectable or metastatic Thymomas B3 and Thymic carcinomas: The CAVEATT study. J. Clin. Oncol. 2020, 38 (Suppl. 15), e21114. [CrossRef]

Publisher's Note: MDPI stays neutral with regard to jurisdictional claims in published maps and institutional affiliations. 